style with that of, say, France. Inevitably, in a study of this nature, some of the authors have been overtaken by events; this being particularly the case with the Czechoslovakian contribution, to which a postscript has been added explaining the possible implications of the democratic revolution. Elsewhere, more normal political developments made much of what has been written somewhat tentative, but this is probably unavoidable in any area of applied ethics today.

Of particular interest among the contributions is an essay by two British scholars, Anne Griffiths and Anne Fink, on the regulation of reproduction in the Third World. By comparison with the demographic disaster engulfing the developing world, the reproductive concerns of the developed countries seem puny, even selfindulgent. In this fascinating essay, the authors examine how western notions of population control have been insensitively imposed on poorer countries by richer countries, and suggest that western ignorance as to the social regulation of human reproduction in non-western countries has contributed in great measure to the failure of population control programmes. The key to greater success is education, especially for women, along with a programme of appropriate social support systems. Tantalising issues are raised: the breakdown of marriage and the traditional family leads to the having of more children out of wedlock. Is marriage, and restraint on extra-marital sexual intercourse, a method of population control? One would have thought so, particularly if there are strong disincentives to an early start to reproduction. Yet the authors are not drawn into a discussion of this, perhaps feeling, as many do, that external moralising on this issue is unwelcome.

ALEXANDER MCCALL SMITH Department of Private Law, University of Edinburgh, Old College,

South Bridge, Edinburgh EH8 9YL

\section{Medicine, money and morals: physicians' conflicts of interest}

M A Rodwin, New York, Oxford University Press, 1993, 411 pages, $\$ 25.00$
Although written from an American perspective, this book is published at a particularly appropriate time in the evolution of the British health service. Mark Rodwin is Associate Professor of Law and Public Policy at Indiana University and in this book he examines the conflicts of interest which arise within the medical profession when decisions relating to patient care are influenced by personal financial incentives.

An opening section introduces how conflicts of interest arise. Society in general, and individuals in particular, expect doctors to act on behalf of their patients. Personal financial incentives or divisions in loyalty can compromise a physician's commitment to patient welfare. The move towards market forces during the 1980 s in both the United Kingdom and the USA has served to exacerbate such conflicts. Professional medical organisations have responded by drawing up ethical guidelines to minimise potential abuses. However, these guidelines themselves reflect a degree of professional ambivalence and in practice have been difficult, it not impossible, to enforce.

A second section illustrates and discusses a range of financial incentives which exist to increase as well as to reduce services. Fee-for-service medicine is an obvious example of a situation whereby generation of additional and possibly unnecessary services will result in additional income. Gifts from medical suppliers and drug manufacturers may also influence choice of treatment. Other practices which are less familiar to British practitioners include payment of 'kickbacks' for referrals or admitting patients to medical facilities in which the physician has a direct or indirect financial interest (physician self-referral). Reducing expenditure by 'risk sharing' may persuade physicians to cut out wasteful tests and procedures but may also act to deprive some patients of necessary care.

In the final section, Rodwin examines the way in which society has coped with conflicts of interest involving other professionals such as lawyers, financial advisers and government officials. These all act as fiduciaries, people with legal obligations to serve others. From a British perspective, the American models and statutes used as illustrations again have their limitations, but he presents a broad range of strategies to minimise potential conflicts. Perhaps the most important is to try and separate financial reward from clinical decision-making. Other measures, such as regulations and sanctions, are likely to prove difficult to implement and monitor. Financial incentives are likely to be the most effective way of influencing clinical decision-making. Whether this is in the individual patient's best interests is debatable and it will undoubtedly undermine the trust which lies at the heart of the doctor/patient relationship. This book should provoke critical reflection on the current reforms in health care.

MALCOLM K BENSON Osler Chest Unit, Oxford Radcliffe Hospital, Headington, Oxford

\section{Forensic psychiatry: clinical, legal and ethical issues} Edited by John Gunn and Pamela
J Taylor, London, Butterworth Heinemann, 1993, 1151 pages, $£ 125.00$

The inclusion of a chapter on ethics in a major textbook is a welcome development for British forensic psychiatry, which to date has lacked both legal and ethical analyses of common clinical problems. This review will focus on this chapter, which is written by the editors.

The issue of morality and psychiatry is discussed at length in the textbook's introduction (page 15). Gunn and Taylor's account sets the framework for their subsequent ethical analysis. They take 'a Darwinian view about the moral sense' (page 17) and state their belief that 'morality is just one way of construing behaviour'. On this account, the ethical conflicts that occur in forensic psychiatric practice $U$ do so because of a difference between the medical and the moral view. The authors note that doctors themselves will have moral views (page 17), but add that 'the languages of morality and of science or medicine should not be confused'.

The chapter on ethics begins with a description of the professional codes of ethics, and notes the abuse of psychiatry for political ends. There is some discussion of the different social roles of the psychiatrist. In balancing the needs of the patients and the 8 needs of society, it is asserted by the authors that 'knowledge' is the most influential factor. There is surprisingly 